\title{
EVALUATION OF RESPIRATORY COMPENSATION IN METABOLIC ALKALOSIS ${ }^{1,2}$
}

\author{
By KATHLEEN E. ROBERTS, J. W. POPPELL, PARKER VANAMEE, ROBERT \\ BEALS, AND HENRY T. RANDALL
}

\author{
(From the Departments of Surgery and Medicine, Memorial Center and Cornell University \\ College of Medicine, and the Andre and Bella Meyer Physiology Laboratories, \\ Sloan-Kettering Institute, New York, N. Y.)
}

(Submitted for publication July 11, 1955; accepted October 27, 1955)

It has been postulated that a metabolic alkalosis could be partially compensated by a decrease in respiratory exchange consequent to inhibition of the respiratory center by an elevated blood $\mathrm{pH}$ (1-5). The extent to which compensation may occur has been predicted to be within the limits imposed by alterations in blood oxygen and $\mathrm{pCO}_{2}$ $(2,5)$. The calculated respiratory exchange which has been predicted with alterations in blood $\mathrm{pH}$ has been challenged on a theoretical basis (6), and the actual occurrence of significant respiratory compensation in metabolic alkalosis has been denied on the basis that no overt decrease in respiratory exchange was noted acutely following the administration of $\mathrm{NaHCO}_{3}$ (7-9). However, there are few data on actual respiratory exchange or plasma $\mathrm{pCO}_{2}$ during acute metabolic alkalosis in unanesthetized animals or human subjects, and the published data are insufficient to permit an evaluation of respiratory compensation in chronic metabolic alkalosis. Accordingly, the studies reported here were carried out on patients and dogs to determine the extent of respiratory compensation in both acute and chronic metabolic alkalosis. The data suggest that respiratory compensation is minimal in the majority of patients and dogs with metabolic alkalosis as produced by bicarbonate infusion, gastric drainage of chloride or potassium deficiency.

\section{METHODS}

The data presented here include analyses of blood $\mathrm{pH}$, plasma carbon dioxide content and calculated plasma $\mathrm{pCO}_{2}$ as determined on 34 patients with metabolic alkalosis and 19 normal patients. Clinically, the types of metabolic alkalosis which were encountered in the pa-

1 This work was supported by USPHS Grants H-1641 and CS-9110 (C6).

2 We are indebted to Dr. Rulon W. Rawson for his cooperation and helpful suggestions in carrying out these studies and to Dr. Robert F. Pitts for reviewing this work. tients included: 1) potassium deficiency alkalosis resulting from post-operative deficits, inadequate intake or hyperadrenocorticism, 2) hypochloremic alkalosis as instigated by gastric drainage or vomiting secondary to upper small bowel obstruction, and 3) alkalosis resulting from exogenous lactate or bicarbonate administration. In the patients presented, the calculated plasma $\mathrm{pCO}_{2}$ and measured $\mathrm{pH}$ were used as an index to determine the extent of respiratory compensation. Carbon dioxide content and $\mathrm{pH}$ in these patients were analyzed either on arterialized venous blood drawn without stasis or directly on arterial blood. 3 In some of the patients, venous blood was drawn without stasis, but was not previously arterialized. The blood was drawn for analysis at a time when the patients had not received sedation. The data from reports in the literature which are incorporated represent analyses which were carried out on unanesthetized dogs or patients with no deducible evidence of pulmonary dysfunction.

The experimental studies were carried out, in the present study, on unanesthetized dogs, and included measurements of minute volume, respiratory rate, alveolar ventilation, plasma carbon dioxide content and blood $\mathrm{pH}$ previous to and during a period of metabolic alkalosis induced either by infusion of sodium bicarbonate or by gastric drainage of chloride.

The animals were trained to stand quietly in a loosely restraining dog sling during the period of metabolic alkalosis. Gastric contents were collected from dogs by an indwelling catheter inserted through a permanent fistula created by the insertion of a biflanged steel button extending from the stomach to the abdominal wall.

In nine alkalotic dogs Sodium Pentothal ${ }^{\circledR}$ was given and the animals were then artificially ventilated to induce a decrease in alveolar ventilation which was just sufficient to reduce the blood $\mathrm{pH}$ to normal, and thus "compensate" the metabolic alkalosis. In these animals

3 The inherent error in utilizing venous blood for analysis of $\mathrm{pH}$ and carbon dioxide must be considered since it is well known that the $\mathrm{pH}$ of venous blood is lower than in arterial blood, whereas the carbon dioxide content is higher. This error was partly obviated by using arterial blood or arterializing venous blood in some of the patients. However, the finding that the $\mathrm{pH}$ and $\mathrm{pCO}_{2}$ did not reflect significant respiratory compensation even with the use of venous blood strengthens the premise, since it would be expected that the error would be in the opposite direction from that reported here. 
arterial oxygen content and oxygen capacity were analyzed.

Arterial blood samples were drawn from an indwelling arterial catheter, and the chemical analyses of carbon dioxide and $\mathrm{pH}$ carried out according to previously described methods (10). Blood oxygen content and capacity were determined in duplicate by the method of Van Slyke and Neill (11). The animals were breathing room air throughout and expired gases were collected in a Tissot Gasometer through a set of valves and a snugly fitted rubber face mask which had a dead space of approximately $35 \mathrm{cc}$. Gas analyses were carried out according to the method of Scholander (12). Physiological dead space was calculated from the Bohr equation as modified by Rahn (13). It was assumed in these calculations that arterial $\mathrm{pCO}_{2}$ was equal to the effective alveolar $\mathrm{pCO}_{2}$ (14). Effective alveolar ventilation was then calculated as follows: Alveolar ventilation $=$ (Tidal volume - Dead space) $\times$ Respiratory rate.

\section{RESULTS}

Figure 1 summarizes the plasma $\mathrm{pH}$ and $\mathrm{pCO}_{2}$ at varying levels of carbon dioxide content in 21 unanesthetized dogs during metabolic alkalosis produced either by alkali infusion or gastric drainage of chloride. The published data of Pitts and Lotspeich (15) are included for comparison. As indicated by this overall summary, the blood $\mathrm{pH}$ increased, whereas the plasma $\mathrm{pCO}_{2}$ remained within the normal range despite elevations in total carbon dioxide.

Although the unchanged plasma $\mathrm{pCO}_{2}$ suggests that pulmonary ventilation is not significantly decreased in metabolic alkalosis, this was further confirmed by direct measurements of minute volume in nine of the animals studied. The data from these nine dogs are summarized in Table I, and show that there was not a consistent decrease in minute volume during metabolic alkalosis. Similarly, the effective alveolar ventilation during metabolic alkalosis was not consistently changed. In some of the animals alveolar ventilation decreased and in others it increased during the pe-
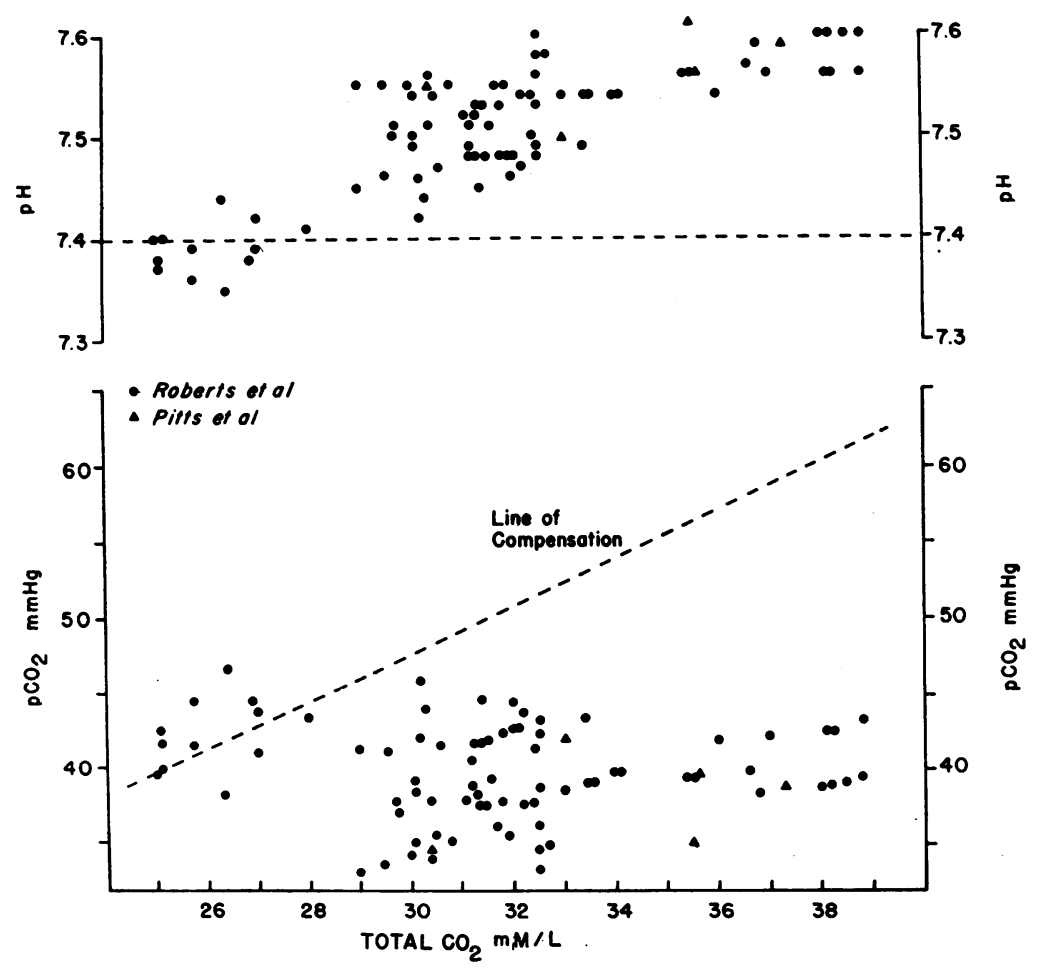

Fig. 1. Blood pH and Plasma pCO, in Relation to Total Carbon Dioxide Content in Alkalotic and Normal Dogs

The line of compensation is calculated from a theoretical consideration of the change in plasma $\mathrm{pCO}_{2}$ which would occur if the metabolic alkalosis were completely compensated, to produce a blood $\mathrm{pH}$ of 7.4. The data of Pitts and Lotspeich (15) are also plotted for comparison. 
TABLE I

Average respiratory minute volume in dogs previous to and during metabolic alkalosis *

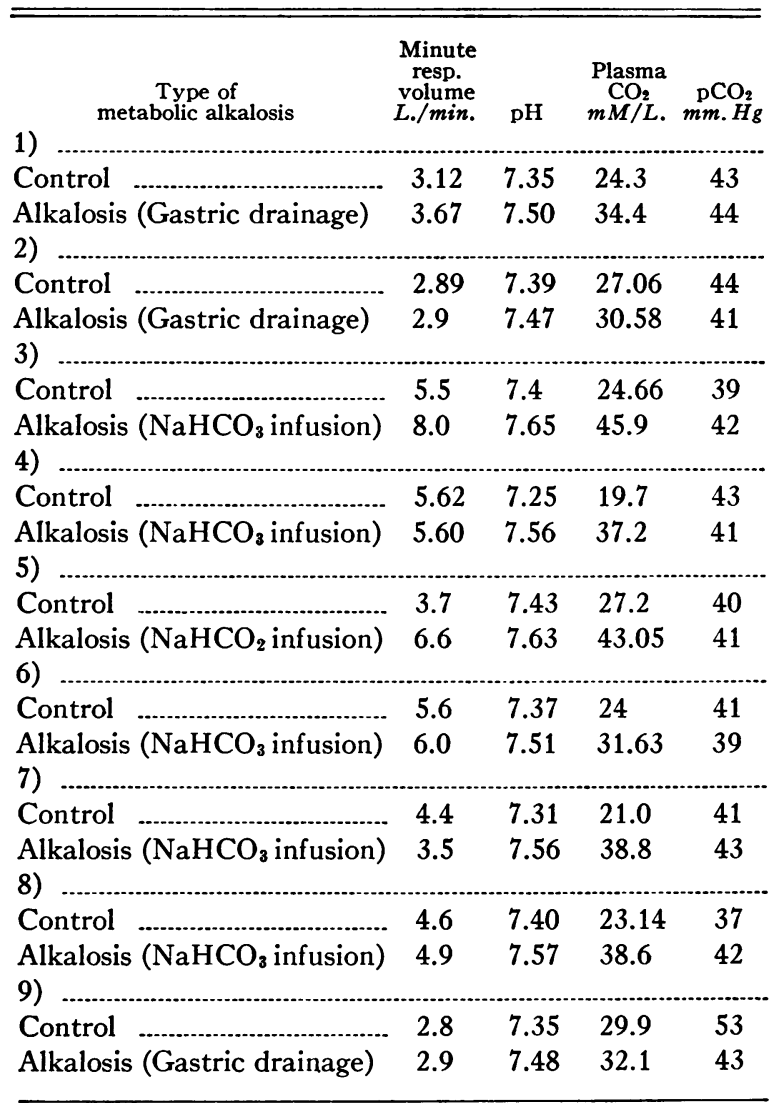

* The respiratory volume represents an average of two to three determinations in the control period and four to six determinations during the alkalotic interval. The plasma values represent single determinations in the control period and at the end of the alkalotic period.

riod of study. This is illustrated in Figure 2, which shows the alveolar ventilation ratio in six of the animals studied. ${ }^{4}$

Table II summarizes the maximal changes in arterial oxygen saturation during a period when alveolar ventilation was reduced sufficiently by anesthesia and artificial ventilation to completely compensate the metabolic alkalosis. In all of the

4 The change in respiration necessary to compensate a metabolic alkalosis could be slight, and may not be detected by the usual methods of measurement. Since a knowledge of the plasma $\mathrm{CO}_{2}$ tension can be utilized to give information regarding the overall ability of the lung to exchange $\mathrm{CO}_{2}(16)$, this is probably a more reliable "index" of the degree to which respiratory compensation occurs in metabolic alkalosis. animals arterial oxygen saturation decreased during the period of artificial compensation. In the five animals who were ventilated sufficiently to restore $\mathrm{pH}$ and $\mathrm{pCO}_{2}$ to alkalotic levels it was noted that arterial oxygen saturation was restored toward control alkalotic values. We have interpreted this observation to indicate that the anesthesia per se had no effect on arterial oxygen saturation and that alterations noted during anesthesia were secondary to decreased pulmonary exchange.

\section{Evaluation of respiratory compensation in patients with metabolic alkalosis}

Figure 3 summarizes the plasma $\mathrm{pCO}_{2}$ and blood $\mathrm{pH}$ in relation to total carbon dioxide content of the plasma in 34 patients studied by the authors. For comparative purposes published data of other authors (17-23) are included. The majority of patients shown demonstrated an elevation of blood $\mathrm{pH}$, while $\mathrm{pCO}_{2}$ was little changed from the normal range. This was true at all levels of plasma carbon dioxide content and regardless of the type of alkalosis encountered. Significant compensation was achieved by only five of the patients summarized from the literature. The remaining fortyfive patients displayed minimal or no respiratory

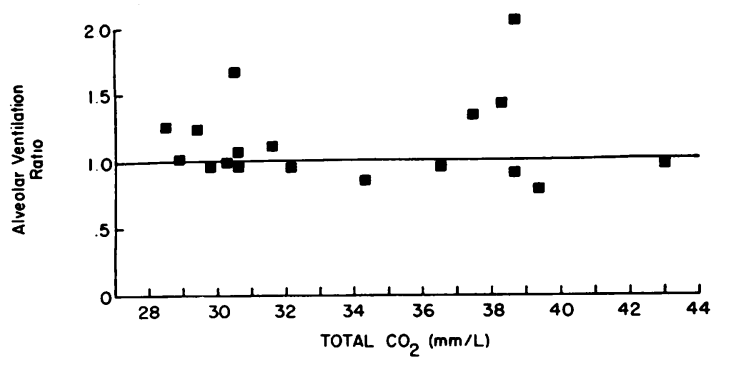

Fig. 2. Alveolar Ventilation Ratio in Dogs during Metabolic Alkalosis

The alveolar ventilation ratio was calculated as follows :

Alveolar ventilation during metabolic alkalosis (L./min.) Control alveolar ventilation (L./min.)

Two measurements of alveolar ventilation were carried out on the animals during the control period and three measurements were carried out during the period of metabolic alkalosis at varying levels of plasma $\mathrm{CO}_{2}$ content and at' a time when the animals had been stabilized at the indicated levels for 30 to 40 minutes. 
TABLE II

Arterial oxygen saturation during the interval of metabolic alkalosis and following artificially induced respiratory compensation*

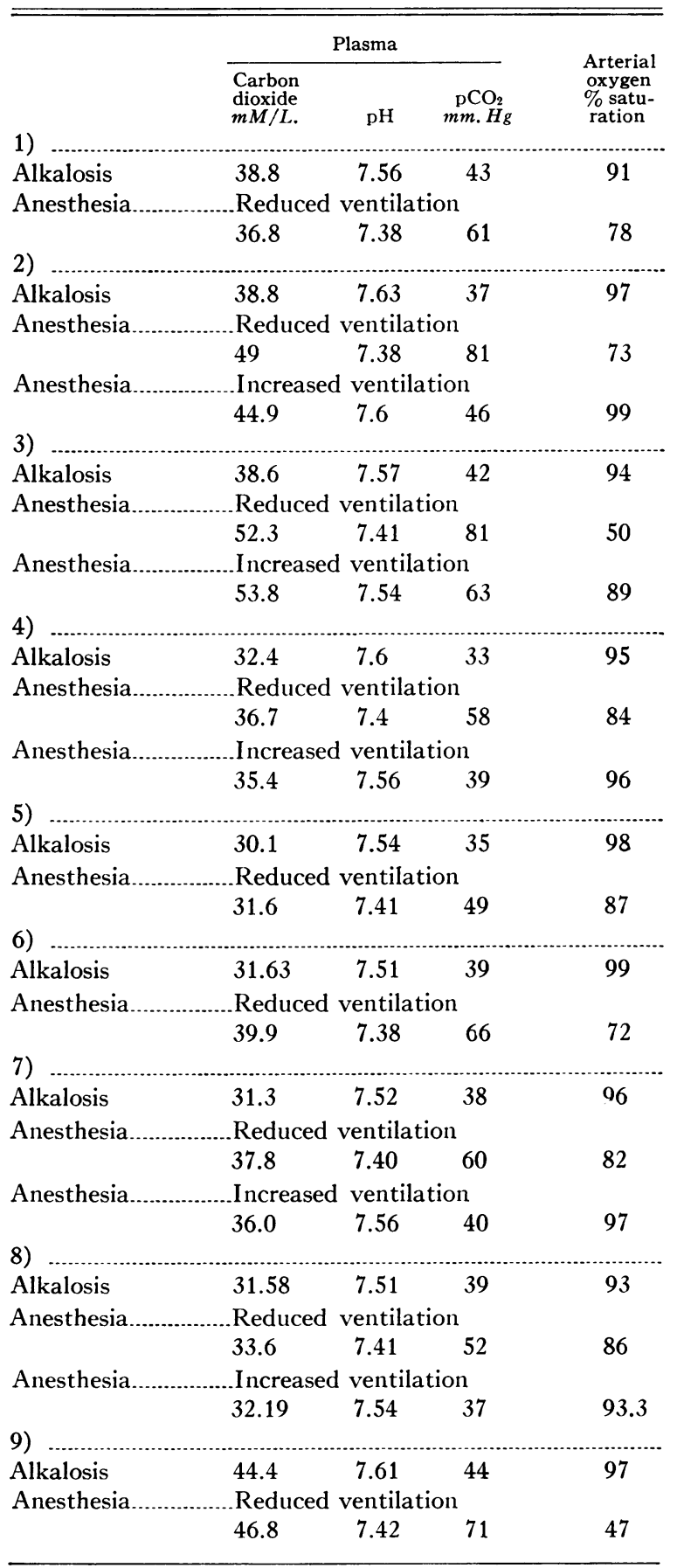

* Arterial $\mathrm{O}_{2}$ was studied in five of the animals who were breathed at a rate sufficient to return plasma $\mathrm{pH}$ and $\mathrm{pCO}_{2}$ toward control alkalotic values. The values shown were determined at a time when the $\mathrm{pH}$ had remained constant for an interval of 20 to 40 minutes. compensation as indicated by the failure of plasma $\mathrm{pCO}_{2}$ to approach the "line of compensation."

\section{DISCUSSION}

The data presented cast doubt on the theoretical prediction that metabolic alkalosis is significantly compensated by an increase in plasma carbon dioxide resulting from a decrease in alveolar ventilation (1-5). In alkalotic dogs this failure was apparent directly from measurements of pulmonary ventilation and indirectly by calculations of plasma $\mathrm{pCO}_{2}$. The finding that the $\mathrm{pH}$ was elevated and plasma $\mathrm{pCO}_{2}$ was little changed from normal in the majority of patients presented, furnished indirect evidence that respiratory compensation is usually minimal in metabolic alkalosis. Conceivably, the interpretations of alveolar ventilation, plasma $\mathrm{pH}$ and $\mathrm{pCO}_{2}$ during acute bicarbonate administration are subject to criticism on the basis that this circumstance does not represent a "steady state" (2). However, the similarity of the findings in the acute experiments, chronic potassium depletion alkalosis and hypochloremic alkalosis weakens this criticism.

The prediction that a decreased respiratory exchange occurs in metabolic alkalosis has presumably been based on the concept that extracellular $\mathrm{pH}$ is one factor which is instrumental in the chemical control of respiration. It is generally agreed that a decrease in plasma $\mathrm{pH}$ results in an increased alveolar ventilation and is partially responsible for compensating a metabolic acidosis $(1-5,24)$. For this reason, it has been assumed that an elevation of plasma $\mathrm{pH}$ would result in the opposite sequence of events. However, any speculation regarding the role of blood $\mathrm{pH}$ in the regulation of respiration must be tempered by a consideration of other factors which are also influential in the chemical control of respiration $(1,2$, $4,6,9)$. The evidence indicating the role of blood oxygen and $\mathrm{pCO}_{2}$ in this respect has led to the hypothesis that respiration is controlled by a variety of interrelated factors and that net alveolar exchange will be the resultant of these integrated forces $(2,5,6)$. The studies reported here augment this thesis and suggest that significant respiratory compensation in metabolic alkalosis may be limited in part by the oxygen requirements of the organism. This consideration is strengthened 


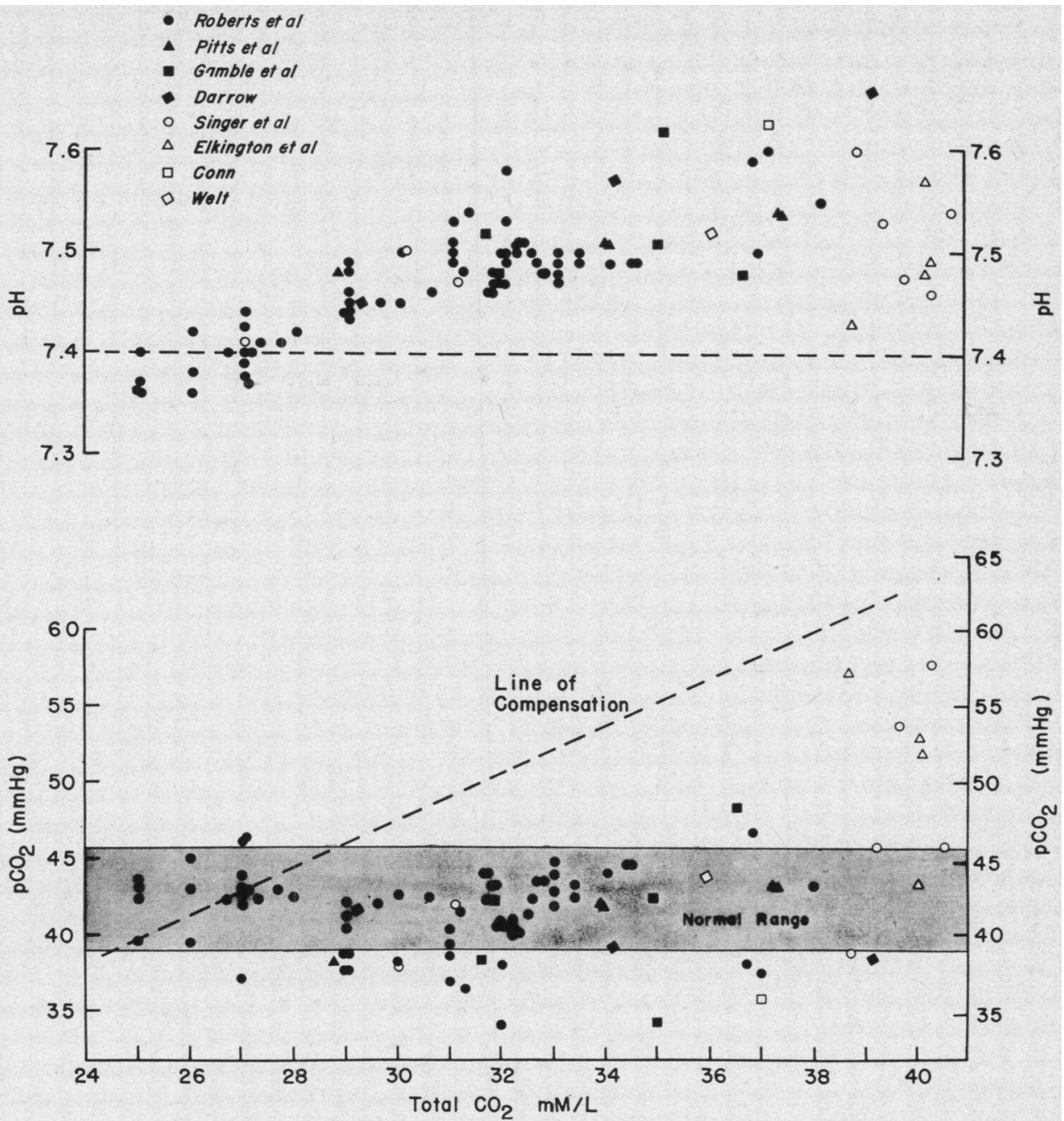

Fig. 3. Blood pH and Plasma pCO ${ }_{2}$ in Relation to Total Carbon Dioxide Content in Alkalotic and Normal Patients

The plotted points represent from one to three separate determinations analyzed in duplicate on each patient. The data are also plotted from patients studied by Pitts (17), Elkinton, Squires, and Crosley (21), Conn (22), Welt (23), Darrow (19), and Gamble, Fahey, Appleton, and Maclachlan (20). The data of Singer, Clark, Barker, Crosley, and Elkinton (18) which have been plotted, represent one $\mathrm{pCO}_{2}$ for each patient taken at the height of alkalosis (i.e., highest total $\mathrm{CO}_{2}$ content). Data from one patient reported by these authors have not been plotted since this patient had a $\mathrm{pCO}_{2}$ which was already abnormally elevated in the central period (R. L.) (1). The stippled area indicates the range of normal values for plasma $\mathrm{pCO}_{2}$ tension.

by the observation that a decrease in arterial oxygen saturation was found in the animals following a decrease in alveolar ventilation sufficient to completely compensate the metabolic alkalosis. However, the data do not permit an evaluation of the extent to which respiratory compensation could theoretically occur, without significant anoxia.

\section{CONCLUSIONS}

1. Respiratory compensation in metabolic alkalosis was found to be minimal in dogs and in the majority of patients shown.

2. In alkalotic dogs no consistent decrease in alveolar ventilation or minute volume was measured. 
3. It has been suggested that changes in arterial oxygen saturation may limit respiratory compensation in metabolic alkalosis.

\section{Addendum}

Since this paper was submitted it has been reported, on the basis of changes in plasma $\mathrm{pCO}_{2}$ that respiratory compensations occur in metabolic alkalosis (Bramlitt, E., and Hardy, J. D., Surgical Forum Program, p. 111, 41st Annual Clinical Congress, American College of Surgeons, 1955). Calculations utilizing either the Van Slyke nomogram or the Henderson-Hasselbalch equation and these authors published data of plasma carbon dioxide combining power (which closely approximates carbon dioxide content) and blood $\mathrm{pH}$ indicates that the average $\mathrm{pCO}_{2}$ of these patients was $34.5 \mathrm{~mm}$. $\mathrm{Hg}$ in the control period and $35.4 \mathrm{~mm}$. $\mathrm{Hg}$ during the alkalotic period. This is a change of doubtful significance and well within the range of experimental error.

\section{REFERENCES}

1. Gray, J. S., The multiple factor theory of respiratory regulation. II. Uncompensated metabolic disturbances of acid-base balance. A.A.F. School of Aviation Medicine. Research Project No. 386.

2. Gray, J. S., Pulmonary Ventilation and Its Physiological Regulation. Springfield, Charles C Thomas, 1950.

3. Peters, J. P., and Van Slyke, D. D., Quantitative Clinical Chemistry, Vol. I, Interpretations. Baltimore, Williams \& Wilkins, 1931.

4. Schmidt, C. F., The Respiration in Macleod's Physiology in Modern Medicine, St. Louis, C. V. Mosby Co., 1941, Part IV, p. 534.

5. Davenport, H., The ABC of acid-base chemistry; the elements of physiological blood-gas chemistry for medical students and physicians. Chicago, Univ. of Chicago Press, 1950.

6. Krueger, H., and Hunter, J., On the multiple factor theory of respiratory control as outlined by Gray. Science, 1947, 105, 463.

7. Schieve, J. F., and Wilson, W. P., The changes in cerebral vascular resistance of man in experimental alkalosis and acidosis. J. Clin. Invest., 1953, 32, 33.

8. West, C. D., and Rapoport, S., Absence of respiratory change or manifest tetany with elevation of plasma $\mathrm{pH}$ produced by bicarbonate administration in dogs. J. Lab. \& Clin. Med., 1950, 36, 428.

9. Gesell, R., The chemical regulation of respiration. Physiol. Rev., 1925, 5, 551.
10. Roberts, K. E., Magida, M. G., and Pitts, R. F., Relationship between potassium and bicarbonate in blood and urine. Am. J. Physiol., 1953, 172, 47.

11. Van Slyke, D. D., and Neill, J. M., The determination of gases in blood and other solutions by vacuum extraction and manometric measurement. J. Biol. Chem., 1924, 61, 523.

12. Scholander, P. F., Analyzer for accurate estimation of respiratory gases in one-half cubic centimeter samples. J. Biol. Chem., 1947, 167, 235.

13. Rahn, H., Comment on Fowler, W. S., Specific tests of pulmonary function in Methods in Medical Research: Vol. 2, J. H. Comroe, Jr., Ed., The Yearbook Publ. Inc., 1950, p. 204.

14. Riley, R. L., Lilientha1, J. L., Jr., Proemmel, D. D., and Franke, R. E., On the determination of the physiologically effective pressures of oxygen and carbon dioxide in alveolar air. Am. J. Physiol., 1946, 147, 191.

15. Pitts, R. F., and Lotspeich, W. D., Bicarbonate and the renal regulation of acid base balance. Am. J. Physiol., 1946, 147, 138.

16. Comroe, J. H., Jr., Interpretation of commonly used pulmonary function tests. Am. J. Med., 1951, 10, 356.

17. Pitts, R. F., Mechanisms for stabilizing the alkaline reserves of the body. The Harvey Lectures, 195253, pp. 172-209.

18. Singer, R. B., Clark, J. K., Barker, E. S., Crosley, A. P., Jr., and Elkinton, J. R., The acute effects in man of rapid intravenous infusion of hypertonic sodium bicarbonate solution. I. Changes in acid-base balance and distribution of the excess buffer base. Medicine, 1955, 34, 51.

19. Darrow, D. C., Congenital alkalosis with diarrhea. J. Pediat., 1945, 26, 519.

20. Gamble, J. L., Fahey, K. R., Appleton, J., and Maclachlan, E., Congenital alkalosis with diarrhea. J. Pediat., 1945, 26, 509.

21. Elkinton, J. R., Squires, R. D., and Crosley, A. P., $\mathrm{Jr}$., Intracellular cation exchanges in metabolic alkalosis. J. Clin. Invest., 1951, 30, 369.

22. Conn, J. W., Presidental address. Part I. Painting background. Part II. Primary aldosteronism, a new clinical syndrome. J. Lab. \& Clin. Med., 1955, $45,3$.

23. Welt, L. G., Clinical Disorders of Hydration and Acid-Base Equilibrium. Boston, Little, Brown, 1955.

24. Poppell, J. W., Roberts, K. E., Vanamee, P., and Randall, H. T., The effect of ventilatory insufficiency on respiratory compensations in metabolic acidosis and alkalosis. In preparation. 